\title{
Consideration of Safety Management When Using Pepper, a Humanoid Robot for Care of Older Adults
}

\author{
Misao Miyagawa1, Yoshihiro Kai², Yuko Yasuhara ${ }^{3}$, Hirokazu Ito ${ }^{3}$, Feni Betriana ${ }^{4}$, \\ Tetsuya Tanioka ${ }^{3}$, Rozzano Locsin $^{3}$ \\ ${ }^{1}$ Department of Nursing, Faculty of Health and Welfare, Tokushima Bunri University, Tokushima, Japan \\ ${ }^{2}$ Department of Mechanical Engineering, Tokai University, Kanagawa, Japan \\ ${ }^{3}$ Department of Nursing, Institute of Biomedical Sciences, Tokushima University, Graduate School, Tokushima, Japan \\ ${ }^{4}$ Graduate School of Health Sciences, Tokushima University, Tokushima, Japan \\ Email: miyagawa@tks.bunri-u.ac.jp
}

How to cite this paper: Miyagawa, M., Kai, Y., Yasuhara, Y., Ito, H., Betriana, F., Tanioka, T. and Locsin, R. (2020) Consideration of Safety Management When Using Pepper, a Humanoid Robot for Care of Older Adults. Intelligent Control and $\mathrm{Au}$ tomation, 11, 15-24.

https://doi.org/10.4236/ica.2020.111002

Received: October 25, 2019

Accepted: December 27, 2019

Published: December 30, 2019

Copyright $\odot 2020$ by author(s) and Scientific Research Publishing Inc. This work is licensed under the Creative Commons Attribution International License (CC BY 4.0).

http://creativecommons.org/licenses/by/4.0/

\begin{abstract}
Pepper, a humanoid robot, is $1.2 \mathrm{~m}$ in height and is designed to move its limbs. There are risks of the older adults experiencing falling and collision accidents when they interact with Pepper. When physical interaction happens between a humanoid robot and human beings, potential harmful physical contact might occur. The aim of this report was to examine the safety management aspects when using Pepper, a humanoid robot for the care of older adults. The older adults' reactions to Pepper's functions cannot be predicted. Hence, it is necessary to clarify methods to guarantee its safety in advance and to increase the safety and properties of the robots. The benefits of introducing support robots such as Pepper for aging medical and nursing care settings are obvious. Therefore, engagement in robot development while considering both the risks and benefits is critical. Our academic initiatives have just begun. Through information exchange among researchers, users, engineers, and law specialists, we need to identify latent and prominent risks in situations where Pepper and the older adults interact and deepen our examination of measures against such risks.
\end{abstract}

\section{Keywords}

Elderly Care, Humanoid Robots, Pepper, Safety Management, Older Adults

\section{Introduction}

In Japan, the number of older people is increasing. In 2019, more than $28 \%$ of the 
population comprises those aged 65 years and more, and this is expected to surpass $35 \%$ by 2040 [1]. On the other hand, the number of healthcare practitioner is decreasing because of the decrease in the working population associated with the declining birthrate [2]. As a countermeasure against these issues which will only increase in severity, the Japanese government proposed implementing "Japan's Robot Strategy" in the five-year period from 2015 to 2020. Part of this strategy is to promote the use of robots in the nursing and medical fields. In particular, there has been a push in recent years toward the use of communication robots for elderly individuals who have low levels of social participation (e.g. older adults living alone) to help them maintain their social activities, promote communication, prevent dementia, and for positive therapeutic effects [3] [4].

In Okayama City, Okayama Prefecture, Japan, PARO (a seal-shaped robot [5]) has been on loan since 2013. PARO is used to prevent dementia in persons requiring nursing care and to reduce caregivers' burden [6] in this context.

In Saijo City, Ehime Prefecture, Japan, a free service using artificial intelligence robots is provided to support the monitoring of the elderly and engage in communication [7] with these individuals. In Kawasaki City, Kanagawa Prefecture, Japan, a demonstration test using Pepper (a robot brand manufactured by SoftBank Robotics Corp; namely, "Pepper") is being conducted for communication with the older adults, maintenance and improvement of their physical functions [8]. Examples of where Peppers had been introduced include hospitals in which the robot performs guidance tasks for outpatients and is used for robot therapy [9], and at nursing facilities for recreation activities during day care [10].

PARO [5], a therapy robot, and Kabochan [11], a communication robot, are both small robots for the elderly with minimal movement. Therefore, there are virtually no risks of physical harm to older adults [12].

Another example is the Telenoid [13], a tele-operated robot with the function to communicate with older adults with Alzheimer's disease [14]. The majority of older adults reported a positive opinion of using Telenoid, and all older adults who interacted with Telenoid gave it a hug without being given any suggestion to do so. This suggests that older adults find cute robots, like Telenoid, to be acceptable use with older adults [15].

On the other hand, Pepper, a humanoid robot, is $1.2 \mathrm{~m}$ in height and is designed to move its limbs [16]. With this movement, there are risks for older adults, such as experiencing falling and collision accidents when they interact with Pepper.

Our research team conducted clinical experiments that used Pepper for rehabilitation and communication purposes at a Long-Term Care Health Facility. In some cases of older adults with dementia care, these older adults approached, touched, and hugged Pepper. Developers might not have expected this reaction to Pepper.

When physical interaction happens between robots and humans, potential harmful physical contact may occur [17]. Although no major accidents have been reported at this time, it is necessary to assume that such situation can occur 
when introducing Pepper, therefore supporting the need to estimate the risks and secure the safety of older adults.

The development of humanoid robots with various functions has been reported in the literature. However, little is known about the safety of human-robot interactions, particularly when dealing with the unpredictable reactions of older adults, especially those with dementia. With the active promotion of introducing humanoid robots, it should not only be an engineering perspective that influences the development of human-robot interactions in the healthcare fields. Providing safe healthcare for patients is the mission of healthcare professionals, therefore, it is an important role for them to provide informed data regarding patient safety especially in human-robot interactive activities.

This review article provides the following content: 1) the definition of a robot and its functions in Japanese settings, 2) safety issues of Pepper to use in older adult care, 3) ways of increasing the safety management of Pepper robot, and 4) future issues regarding the introduction of Pepper into the clinical settings.

The aim of this report was to examine the safety management aspects when using Pepper, a humanoid robot for the care of older adults.

\section{Methods}

The research group, comprised of the authors of this paper, has been conducting research studies from 2017. Our studies focus on the promotion of communication and rehabilitation of older adults by using Pepper [18] [19]. Pepper is a humanoid robot that is equipped with rehabilitation and communication functions. It is usually used for residents in a nursing home and for older adults attending the day service. During this process, we held two expert meetings (in April and July 2019) involving nursing, physiotherapy, and engineering researchers, as well as lawyers to ensure the patients' safety.

\section{Results and Discussion}

\subsection{Definition of Robot in Japan}

The Ministry of Health, Labor and Welfare, Japan, defines a robot as an intellectualized mechanical system that possesses three technological capabilities: "perceiving information (sensor system)", "making judgments (intelligence and control system)", and "operating (drive system)" [20].

Among various types of robots are industrial and human-friendly robots. Industrial robots are mostly automated and used in industrial settings to improve the manufacturing process. Human-friendly robots are placed in the spaces in which people live, and support the so-called self-expression of humans, such as the actions in their work and daily life. Care assistance and communication robots are included among these robots [12].

\subsection{Safety Issues of Pepper to Use the Elderly Care}

This study focused on the physical safety of older adults facilitated by introduc- 
ing Pepper into nursing homes.

Pepper has interaction functions such as talking to older adults to encourage participation, and shake its hands thereby encouraging older adults to touch it [21]. In addition, a language program emulating a six-year-old child is integrated into the program of Pepper, creating the feeling of interacting with a grandchild. Therefore, these are some elements that make older adults want to approach and touch Pepper.

Even in the clinical experiments on conversation with older adults using Pepper, it was observed in many instances that they touched Pepper's hand or head and hugged it during the middle or at the end of their conversation.

In addition, a self-propelling function is being considered for the next generation of Pepper [22]. Although not reported thus far, there is a possibility that an older adult could approach Pepper, resulting in a collision accident such as a fall.

\subsection{Ways of Increase the Safety Management of Pepper}

In industrial robots, safety of humans is guaranteed by isolating the robots from humans with safety measures such as safety guards [23], a contraption that ensures safety when the robot is operating to prevent humans from coming into contact with robots. However, this environmental concern is not possible with Pepper, when used in elderly care settings. Therefore, it is necessary to ensure a systematic safety feature of this robot.

It would be desirable to guarantee that people do not enter the operational range of the robot. Thus, it is important to consider supervisory control when using robots [24]. However, it is not possible to avoid robots and people close contact in the case of Pepper and other robots used in nursing care and rehabilitation sites. Hence, it is necessary to implement a system to minimize the possible harm to the user.

Pepper is controlled by a computer so that its upper limbs will stop moving if a person approaches the turning range of its upper limbs. An emergency stop button, that people in close proximity with Pepper can press when the computer malfunctions, is also installed on Pepper's main body. Moreover, it is also installed with precautions such as covering its arm with a soft material. In addition, the fingers on Pepper's hands have an extremely breakable structure. Therefore, even if an older adult touches or holds Pepper's hands, it is equipped with a safety function that reduces any potential physical harm to people. The existing safety features of Pepper are shown in the following Figure 1.

In the risk management process, it is vital to identify the potential harm and determine the associated risks [17]. In this case, even though Pepper is equipped with safety features, some safety risks still remain. For example, if an older adult suddenly and carelessly comes too close or touches Pepper on different parts of its body: 1) Pepper might fall and potentially drag the older adult or 2) the older adult might get caught in Pepper's arms or joints. Furthermore, there is a risk of Pepper causing a collision accident with older adults, 3) when the robot becomes 


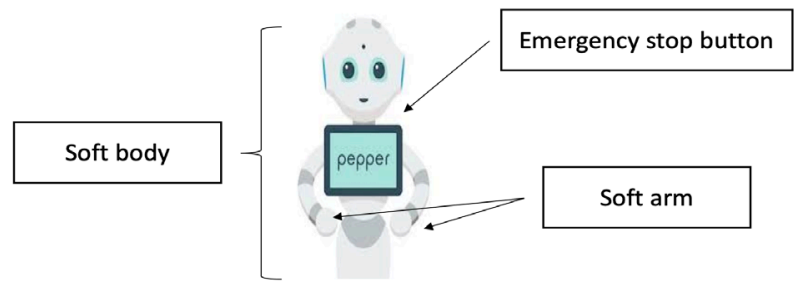

Figure 1. The safety features of Pepper.

uncontrollable because its computer or sensors malfunction and the people in close proximity are unable to press the emergency stop button. In particular, if Pepper's hands are operated at a rapid speed while in an uncontrollable state, its fingers might ram into people's eyes even though they are made to break easily. In addition, if Pepper was to become uncontrollable, there is a risk that its arms will collide people at a high-speed or that a person might get caught in Pepper's arms or joints. Furthermore, when Pepper is able to self-propel using wheels, it will be required to operate on slopes, and not just on a flat floor. In this case, should Pepper's battery run out on a slope, 4) there is the potential risk of it plummeting downward at a high speed because of gravity, and consequently colliding with someone at a high speed.

As a safety measure against the abovementioned 1), namely getting dragged down when Pepper falls down, measures such as "widening the installation area with the ground" and "widening the space between the wheels" are proposed to make Pepper less likely to fall. As a countermeasure to 2), namely people getting caught in Pepper's arms or joints, installing pressure sensors on the surface of the Pepper's body to make it stop by detecting if someone has been caught in its arms or joints is proposed [25] [26].

In addition, as a countermeasure against 3), namely Pepper becoming uncontrollable because of a malfunction of its computer or sensor, and the people around Pepper being unable to press the emergency button, equipping speed-based and contact force-based mechanical safety devices [27] is proposed. The speed-based mechanical safety device mechanically detects when Pepper's joint moves at an unexpectedly high speed and stops the Pepper's movement. The contact force-based mechanically safety device detects and stops Pepper mechanically when it comes into contact with a person with an unexpectedly high contact force. Both speed-based and contact force-based safety devices use no battery, controller, or motor and are composed only of passive mechanical elements such as a panel. Therefore, they operate even if Pepper's computer is not functioning, or its battery dies. Additionally, wearing goggles is proposed in order to prevent Pepper's fingers from ramming into people's eyes. As a countermeasure against 4), namely that if Pepper's battery dies on a slope, there is a risk of Pepper going down the slope at a high speed because of gravity and colliding with a person at a high speed, a possible proposal is to use the abovementioned speed-based mechanical safety device for the wheels. As it was described earlier, a speed-based mechanical safety device does not require a battery and 
will function when a high-speed event occurs on a slope.

The following table (Table 1 ) exhibits the summary of the safety management for Pepper.

Furthermore, we should not forget the additional measures required in terms of users' movements when utilizing Pepper in caring for older adults. For example, sometimes, elderly individuals with dementia move in ways that cannot be predicted by medical practitioners. As such, Pepper's safety functions and the abovementioned safety countermeasures alone are possibly not enough to handle such movements. As a current countermeasure, a procedure is necessary whereby Pepper's safety is ensured by having only nurses handle it, becoming intermediaries between Pepper and older adults. In addition, all intermediaries are required to know all of Pepper's usage rules and instructions. It is important that the intermediaries receive safety education (e.g., measures required during an emergency), and not only operating training. It is indispensable to train personnel with the skills to deal with and resolve any types of problems with the robot, allocating them as intermediaries between the robots and the elderly to develop a human safety management system.

\subsection{Future Issues Regarding the Clinical Introduction of Pepper}

Medical staff members are required to fulfill their duty of care. This duty of care includes predicting risks and intervening by establishing measures to avoid such risks. Nurses working in hospitals make efforts to prevent medical accidents by undergoing training to increase risk sensitivity and reflection, even in the case of a minor incident (an accident that has not caused injury to the patient).

Table 1 . The safety management for Pepper.

\begin{tabular}{|c|c|}
\hline The physical safety risks & The countermeasures \\
\hline 1) Pepper falls and older adults get involved & $\begin{array}{l}\text { Widening the installation area with the ground. } \\
\text { Widening the space between the wheels. }\end{array}$ \\
\hline $\begin{array}{l}\text { 2) Older adults getting caught in Pepper's } \\
\text { joints }\end{array}$ & $\begin{array}{l}\text { Installing pressure sensors on the surface of Pepper's } \\
\text { body. }\end{array}$ \\
\hline \multicolumn{2}{|l|}{$\begin{array}{l}\text { - Pepper's hands and fingers move at high } \\
\text { speed, hit to human eyes at high speed. }\end{array}$} \\
\hline $\begin{array}{l}\text { - Pepper's arms collide with an older adult } \\
\text { at high speed. }\end{array}$ & $\begin{array}{l}\text { Equipping speed-based and contact force-based } \\
\text { mechanical safety devices. }\end{array}$ \\
\hline $\begin{array}{l}\text { - Older adult caught between Pepper's } \\
\text { arms and joints. }\end{array}$ & Wearing goggles. \\
\hline \multicolumn{2}{|l|}{$\begin{array}{l}\text { - Pepper's fingers ram into people's } \\
\text { eyes. }\end{array}$} \\
\hline \multicolumn{2}{|l|}{ 4) Pepper's battery dies on a slope } \\
\hline $\begin{array}{l}\text { - When the battery of Pepper runs out on } \\
\text { the slope, it descends at a high speed due } \\
\text { to gravity and collides with people at a } \\
\text { high speed. }\end{array}$ & Speed-based mechanical safety device for the wheels. \\
\hline
\end{tabular}


In medical settings, the risk management approach of foolproof, fail-soft, and fail-safe measures is starting to permeate.

Foolproof: To avoid accidents and incidents, any organization should have multiple layers of controls or defenses in place. However, controls are never foolproof [28].

Fail-soft. It is defined as a failure in the performance of some component part of a system without immediate major interruption, or failure in the performance of the system as a whole and/or sacrifice in the quality of the product [29].

Fail-safe: This is a strategy to mitigate hazards, and an approach that works to avoid incidents, for example, automatic instant shut down mechanisms [30]. Also, a fail-safe relies on the idea that should anything fail, safety is not jeopardized, for example, the use of electrical switches that cut power when they fail [31].

Furthermore, when introducing new systems and machines into a clinical setting, it is important to introduce them after estimating the risk and to adopt countermeasures against such risks using methods such as the Failure Mode and Effects Analysis (FMEA) [32]. In Japan, the use of the Pepper Robot in aging care sites has just begun. Therefore, it is necessary to increase the efficacy of robot-provided care while performing risk management and accumulating sufficient evidence.

\section{Conclusions}

Older adults' reactions to Pepper's functions cannot be predicted. Hence, it is necessary to clarify methods to guarantee its safety in advance and to increase the safety and properties of the robots. The benefits of introducing support robots such as Pepper for aging medical and nursing care settings are obvious. Therefore, engagement in robot development while considering both the risks and benefits is critical.

Our academic initiatives have just begun. Through information exchange among researchers, users, engineers, and law specialists, we need to identify latent and prominent risks in situations where Pepper and the older adults interact and deepen our examination of measures against such risks. This study provides new insights into safety management concerns using Pepper over the existing safety features that equip the recent Pepper version. The information obtained from this study is expected to be taken into consideration for further and future development of Pepper.

\section{Acknowledgements}

This work was supported in part by JSPS KAKENHI Grant Number JP17H01609, JP19K10735, Pfizer Health Research Foundation 2018.

\section{Conflicts of Interest}

The authors declare no conflicts of interest regarding the publication of this paper. 


\section{References}

[1] Cabinet Office, Government of Japan (2019) The Situation and Future of the Elderly, White Paper on Aging Society (Overall Version). (In Japanese) https://www8.cao.go.jp/kourei/whitepaper/w-2019/zenbun/pdf/1s1s_01.pdf

[2] Ministry of Health, Labor and Welfare (2017) Changes in Labor Force: Annual Report on Health, Labor and Welfare. (In Japanese) https://www.mhlw.go.jp/wp/hakusyo/kousei/17-2/dl/01.pdf

[3] Ministry of Health, Labor and Welfare (n.d.) Appendix 5-3 Welfare Tools Related to Priority Areas in the Use of Robot Technology for Nursing Care. (In Japanese) https://www.mhlw.go.jp/file/05-Shingikai-12301000-Roukenkyoku-Soumuka/00000 94783.pdf

[4] Robinson, H., Macdnald, B. and Sroadbent, E. (2014) The Role of Healthcare Robots for Older People at Home: A Review. International Journal of Social Robotics, 6, 575-591. https://doi.org/10.1007/s12369-014-0242-2

[5] Daiwa House Industry Co. Ltd. (n.d.) Seal-Type Therapeutic Robot PARO. (In Japanese) https://www.daiwahouse.co.jp/robot/paro

[6] Okayama City (n.d.) Nursing Care Equipment Lease Model Projects. (In Japanese) http://www.city.okayama.jp/hofuku/hokenfukushiseisaku/hokenfukushiseisaku_000 84.html

[7] Saijyo City Official Website (2019) Why Not Use AI Robots to Watch over the Elderly? (In Japanese)

https://www.city.saijo.ehime.jp/soshiki/hokatsushien/h30komyuroboriyousyabosyu $\underline{\text { u.html }}$

[8] Robostart Inc. (2015) Started Pepper Demonstration Experiment to Introduce Nursing Care Facilities. (In Japanese) https://robotstart.info/2015/06/16/report-robot-pepper_jissho.html

[9] SoftBank Robotics (n.d.) Introduction Example for Pepper Biz (Juntendo Hospital). (In Japanese) https://www.softbank.jp/biz/robot/pepper/case/juntendo

[10] SoftBank Robotics (n.d.) Introduction Example for Pepper Biz (Ittokai, Social Welfare Corporation). (In Japanese) https://www.softbank.jp/biz/robot/pepper/case/ittokai

[11] Pip Robot Technology Co. (n.d.) Product Introduction (Unazuki Kabo-Chan). (In Japanese) https://www.piprt.co.jp/products.html

[12] Mukaido, M. (2013) The Outline of Robot Safety Technology and the Latest Trends. Robo, 211, 3-9.

[13] ATR Hiroshi Ishiguro Laboratory (n.d.) Telenoid. http://www.geminoid.jp/projects/kibans/Telenoid-overview.html

[14] Kuwamura, K., Nishio, S. and Sato, S. (2016) Can We Talk through a Robot as If Face-to-Face? Long-Term Fieldwork Using Teleoperated Robot for Seniors with Alzheimer's Disease. Frontier in Psychology, 7, 1066. https://doi.org/10.3389/fpsyg.2016.01066

[15] Ogawa, K., Nishio, S., Koda, K., Balistreri, G., Watanabe, T. and Ishiguro, H. (2011) Exploring the Natural Reaction of Young and Aged Person with Telenoid in a Real World. Journal of Advanced Computational Intelligence and Intelligent Informatics, 15, 592-597. https://doi.org/10.20965/jaciii.2011.p0592

[16] SoftBank Robotics (n.d.) Pepper. https://www.softbankrobotics.com/emea/en/pepper

[17] Vasic, M. and Billard, A. (2013) Safety Issues in Human-Robot Interactions. Pro- 
ceeding of IEEE International Conference on Robotics and Automation, Germany, 197-204.

[18] Tanioka, R., Sugimoto, H., et al. (2019) Characteristics of Transactive Relationship Phenomena among Older Adults, Care Workers as Intermediaries, and the Pepper Robot with Care Prevention Gymnastics Exercises. The Journal of Medical Investigation, 66, 46-49. https://doi.org/10.2152/jmi.66.46

[19] Miyagawa, M., Yasuhara, Y., et al. (2019) The Optimization of Humanoid Robot's Dialog in Improving Communication between Humanoid Robot and Older Adults. Intelligent Control and Automation, 10, 118-127. https://doi.org/10.4236/ica.2019.103008

[20] Ministry of Health, Labor and Welfare (2018) Development and Popularity of Robots. (In Japanese) https://www.mhlw.go.jp/stf/seisakunitsuite/bunya/0000209634.html

[21] Japan Agency for Medical Research and Development (2018) Project on the Development and Promotion of Introducing Robots and Nursing Care Devices (Standards Formulation and Evaluation Project): Research on the Development of Robotic Nursing Equipment Robot List. (In Japanese)

https://www.amed.go.jp/content/000003887.pdf

[22] SoftBank Robotics (n.d.) Pepper. (In Japanese) https://www.softbankrobotics.com/jp/product/biz3/spec

[23] Retsch, T.S. and Guido Marty, A. (2011) Safety Principles for Industrial Robots. http://iloencyclopaedia.org/part-viii-12633/safety-applications/94-58-safety-applicat ions/safety-principles-for-industrial-robots

[24] Chen, J.Y.C., Barnes, M.J. and Harper-Sciarini, K. (2011) Supervisory Control of Multiple Robots: Human-Performance Issues and User-Interface Design. IEEE Transactions on Systems, MAN, and Cybernetics Part C: Applications and Reviews, 41, 435-453. https://doi.org/10.1109/TSMCC.2010.2056682

[25] Iwata, H. and Sugano, S. (2009) Design of Human Symbiotic Robot TWENDY-ONE. Proceeding of IEEE International Conference on Robotics and Automation, Kobe, 580-586. https://doi.org/10.1109/ROBOT.2009.5152702

[26] Elkmann, N., Fritzsche, M. and Schulenburg, E. (2011) Tactile Sensing for Safe Physical Human-Robot Interaction. Proceeding of ACHI: The Fourth International Conference on Advances in Computer-Human Interactions, Lausanne, 212-217. https://doi.org/10.1145/1957656.1957700

[27] Kai, Y. and Sando, S. (2014) Development of a Velocity and Contact Force-Based Mechanical Safety Device for Service Robots. Proceeding of IEEE International Conference on Automation Science and Engineering, Taipei, 1188-1193. https://doi.org/10.1109/CoASE.2014.6899477

[28] Civil Aviation Safety Authority, Australian Government (2012) Safety for Aviation: A Practical Guide Safety Risk Management. https://www.casa.gov.au/sites/g/files/net351/f/_assets/main/sms/download/2012-sm s-book3-safety-risk-management.pdf

[29] National Bureau of Standards, United States of America (1981) A Glossary of Terms for Robotics.

https://www.govinfo.gov/content/pkg/GOVPUB-C13-7a9025561f229e1f7fb504ace8 52d602/pdf/GOVPUB-C13-7a9025561f229e1f7fb504ace852d602.pdf

[30] Koopman, P. (2015) Critical Systems and Software Safety. https://users.ece.cmu.edu/ koopman/lectures/ece649/20_critical_systems.pdf

[31] Wong, W. (2010) Inherently Unsafe: Safety Issues in Planning a New Facility. In: 
The Risk Management of Safety and Dependability: A Guide for Directors, Managers and Engineers, Woodhead Publishing Limited, Cambridge, 145-164. https://doi.org/10.1533/9781845699383.145

[32] Katsuhige, O. (2005) The Practical FEMA Methods in the Global Standard Era: Quality Management and Reliability, Integrity, Safety Analysis. JUSE Press, Tokyo. 